\title{
Specific Heat and Thermal Expansion Coefficient of Hybrid Epoxy Composites
}

\author{
GEORGEL MIHU, VASILE BRIA, ADRIAN CIRCIUMARU, IULIAN GABRIEL BIRSAN, \\ MARINA BUNEA*
}

Dunarea de Jos University of Galati, Research and Development Center for Thermoset Matrix Composites, 47 Domneasca Str., 800008, Galati, Romania

Abstract: Thermal behavior of hybrid epoxy composites reinforced with different types of plain weave fabrics and ply orientation at various angles was investigated in this research. It was analyzed their thermal linear expansion coefficient and specific heat measured with Thermomechanical Analyzer (TMA) and Differential Scanning Calorimeter (DSC) respectively. Also, in this paper was studied the influence of carbon black - aramid powder and carbon black - barium ferrite mixtures added into epoxy matrix between certain plies of the hybrid composites. The experimental results showed that the addition of filler mixtures led to a significant decreasing of thermal expansion coefficient and specific heat of the hybrid epoxy composite with carbon outer plies. It was recorded a good structural stability in case of hybrid carbon-glass composite in the temperature range of $40-60^{\circ} \mathrm{C}$.

Keywords: hybrid composite, filled epoxy matrix, specific heat, linear expansion coefficient

\section{Introduction}

The polymeric composites are lightweight advanced multifunctional engineering materials used in all the domains due to their properties and low cost. Their superior characteristics are obtained by combination of the advantageous and desirable properties of their structural constituents. Generally, the polymeric composites are made of two phases: matrix and reinforcement. In dependence of the application, in many cases it is necessary to improve their physical or mechanical properties required for application's special conditions in which these materials will be exploited. Often, the composite materials are used in application with variations in temperature. In this case it is known that with the temperature increasing grows their ductility and with the temperature decreasing grows their fragility. So, in order to improve their mechanical resistance at low or high temperatures without affecting their other properties, various types of fillers and/or reinforcements can be used, taking into account their compatibility with the used polymer matrix, adherence capacity, shape and dimensions, quality and properties of filler-matrix and fiber-matrix interphases that they can provide. Most often in application with variation in temperature composite materials with epoxy matrix are used. These epoxy matrix can be modified by addition of metallic (aluminum [1,2], copper [3, 4], nickel [5], silver [6, 7], etc.), ceramic (alumina [8, 9], silicon carbide [10,11], boron nitride [9, 12], halloysite nanotubes [13] etc.) or carbonaceous (single- [14] or multi-walled [15-17] carbon nanotubes [18], graphene [6, 15, 16, 18-20], carbon black [18, 21, 22], graphite [11, 15, 18]) fillers.

As reinforcement for epoxy composites there can be used different types of fibers and/or fabrics to form hybrid stratified materials with high mechanical resistance at temperature variation. As reinforcement, usually, there are used the glass, carbon, aramid fibers or their combinations and fabrics weaved from these fibers. More thermal stable composite materials can be obtained by carbon-glass hybridization of epoxy composites, considering that the glass fiber reinforced epoxy composites show positive values of thermal expansion coefficient on both directions relative to the fiber and the values sign of this thermal parameter presented by carbon fiber reinforced epoxy composites depends on fiber direction. The composites reinforced with unidirectional carbon fibers exhibits negative thermal expansion coefficient in longitudinal direction as compared to the ones reinforced with carbon plain weave fabrics, which presents positive values of this thermal parameter [23].

*email: marina.bunea@ugal.ro 
In ref. [24] it was investigated of fiber orientation between $0^{\circ}$ and $90^{\circ}$ and hybridization on thermal expansion coefficient at cryogenic conditions of unidirectional glass, carbon, carbon - glass fibers epoxy laminates. It was found that glass epoxy composite presented positive values for all angles of fiber orientation and carbon epoxy composite showed negative values for fiber orientation between $0^{\circ}$ and $30^{\circ}$. As a result it was obtained the hybrid composite made of carbon fibers in $80 \%$ volume fraction with fiber orientation at $30^{\circ}$ and glass fibers in $20 \%$ volume fraction with fiber orientation at $0^{\circ}$, which exhibited a thermal coefficient with values near zero.

In this research it was investigated the influence of carbon black - aramid powder and carbon black - barium ferrite mixtures added into epoxy matrix between certain plies of the fabric reinforced hybrid composites with fiber orientation at various angles $\left(0^{\circ}, \pm 15^{\circ}, \pm 30^{\circ}, 45^{\circ}\right.$ and $\left.90^{\circ}\right)$ on their specific heat and thermal linear expansion coefficient. The medial ply of all hybrid composites was made of a hybrid fabric with a warp realized by alternating two carbon fiber yarns and one aramid fiber yarn while the weft is realized by alternating one yarn of carbon fibers, one yarn of aramid fibers and one yarn of glass fibers together with a tinned cooper wire of $0.2 \mathrm{~mm}$ diameter. So, it was analyzed the thermal behavior of the epoxy laminate with all plies made of this hybrid fabric in order to determine the influence of this ply on the thermal behavior of hybrid epoxy composites.

\section{Materials and methods}

\subsection{Materials}

EPIPHEN epoxy bicomponent system RE 4020 - DE 4020 (Bostik) was selected as epoxy matrix for hybrid composite materials reinforced with fabrics. The ratio between the epoxy resin and the hardener of this system is 100:30. This epoxy system was selected due to its high compatibility and adherence capacity to all fiber types and to a wide range of fillers, physical properties of pre-polymer mixture important for material formation technique and electrical, thermal and mechanical properties of complete polymerized mixture.

Four plain woven fabric types were chose as reinforcement for hybrid composite materials due to the fact that they exhibits almost the same mechanical properties on both warp and weft yarn directions [25]: G - EC9 fiberglass weaving yarn with 68tex linear density, fabric $163 \mathrm{~g} / \mathrm{m}^{2}$ specific density and $0.18 \mathrm{~mm}$ thickness; A - 2200 aramid weaving yarn with 1210dtex linear density, fabric $173 \mathrm{~g} / \mathrm{m}^{2}$ specific density and $0.28 \mathrm{~mm}$ thickness; $\mathrm{C}-3 \mathrm{~K}$ carbon weaving yarn with 200 tex linear density, fabric $160 \mathrm{~g} / \mathrm{m}^{2} \mathrm{specific}$ density and $0.26 \mathrm{~mm}$ thickness; $\mathrm{M}$ - the above described hybrid fabric with $270 \mathrm{~g} / \mathrm{m}^{2}$ specific density and $0.33 \mathrm{~mm}$ thickness.

In order to enhance the impact performance, mechanical strength, thermal and electrical properties and to achieve the multifunctional advanced epoxy composites there were selected different types of fillers based on previous experimental results, such as potatoes starch, carbon black, aramid powder and barium ferrite. For this investigation the potatoes starch was selected in order to avoid the sedimentation and clustering of the carbon black and barium ferrite, due to its swelling into liquid and to ensure uniform distribution of the other fillers into polymer mixtures. Also, this filler was used taking in account that the amount of $10 \%$ corn starch exhibits no effects on mechanical, electrical and thermal properties of epoxy composites according to experimental results presented in ref. [26]. The aramid powder was used to improve the impact resistance and mechanical properties of the hybrid epoxy composites, the carbon black was added to enhance thermal and electrical properties and barium ferrite to improve magnetic behavior.

\subsection{Preparation of hybrid composites}

Two classes Hx.1 and Hx.2 of hybrid epoxy composite materials with ply orientation at various angles $\left(0^{\circ}, 15^{\circ}, 30^{\circ}, 45^{\circ}, 60^{\circ}, 75^{\circ}\right.$ and $\left.90^{\circ}\right)$ were formed for this study. The composites of both material classes present the same layer configuration but different type of epoxy matrix. The ply configuration of the hybrid epoxy composite materials is presented in Table 1. For each class there were formed six hybrid epoxy composites reinforced with fabrics and ply orientation at various angles made of 17 layers, 
which were asymmetrically arranged relative to the medial ply (hybrid fabric lamina). Also, in order to study the influence of medial ply on thermal behavior of the hybrid composites, it was formed for each an epoxy composite reinforced with hybrid fabric and ply orientation at $90^{\circ}$, named here $\mathrm{HE}$ and $\mathrm{HF}$. The hybrid fabric was obtained by modifying of plain mixed Toray $3 \mathrm{~K}$ carbon weaving yarn with 200 tex linear density and Kevlar® 49 weaving yarn with 1580dtex linear density. The specific density of mixed carbon/aramid fabric with $0.23 \mathrm{~mm}$ thickness was $165 \mathrm{~g} / \mathrm{m}^{2}$. This mixed fabric presented a woven geometry of 2 carbon yarns alternated by 1 aramid yarn (2:1) in the warp direction and 1 carbon yarn alternated by 2 aramid yarns (1:2) in the weft direction. The transformation of this fabric was performed handmade by replacement in the weft direction of each second aramid yarn with a 200tex fiberglass and a $0.2 \mathrm{~mm}$ diameter tinned copper wire $[27,28]$.

Table 1. Layer configuration of the hybrid epoxy composites of class Hx.y materials (y is 1 or 2 )

\begin{tabular}{c|cccccccccccccccccc}
\hline Mat. & \multicolumn{11}{|c}{ Layer configuration } \\
\hline H1y & $\mathrm{A}_{30}$ & $\mathrm{~A}_{60}$ & $\mathrm{C}_{45}$ & $\mathrm{C}_{0}$ & $\mathrm{C}_{45}$ & $\mathrm{C}_{0}$ & $\mathrm{~A}_{15}$ & $\mathrm{~A}_{30}$ & $\mathrm{M}_{90}$ & $\mathrm{~A}_{60}$ & $\mathrm{~A}_{75}$ & $\mathrm{C}_{0}$ & $\mathrm{C}_{45}$ & $\mathrm{C}_{0}$ & $\mathrm{C}_{45}$ & $\mathrm{~A}_{30}$ & $\mathrm{~A}_{60}$ \\
$\mathrm{H} 2 \mathrm{y}$ & $\mathrm{A}_{15}$ & $\mathrm{~A}_{30}$ & $\mathrm{C}_{75}$ & $\mathrm{C}_{60}$ & $\mathrm{G}_{45}$ & $\mathrm{C}_{15}$ & $\mathrm{~A}_{30}$ & $\mathrm{~A}_{45}$ & $\mathrm{M}_{90}$ & $\mathrm{~A}_{45}$ & $\mathrm{~A}_{60}$ & $\mathrm{C}_{75}$ & $\mathrm{G}_{45}$ & $\mathrm{C}_{30}$ & $\mathrm{C}_{15}$ & $\mathrm{~A}_{60}$ & $\mathrm{~A}_{75}$ \\
$\mathrm{H} 3 \mathrm{y}$ & $\mathrm{A}_{30}$ & $\mathrm{~A}_{15}$ & $\mathrm{C}_{0}$ & $\mathrm{G}_{45}$ & $\mathrm{G}_{60}$ & $\mathrm{C}_{75}$ & $\mathrm{~A}_{30}$ & $\mathrm{~A}_{45}$ & $\mathrm{M}_{90}$ & $\mathrm{~A}_{45}$ & $\mathrm{~A}_{60}$ & $\mathrm{C}_{15}$ & $\mathrm{G}_{30}$ & $\mathrm{G}_{45}$ & $\mathrm{C}_{0}$ & $\mathrm{~A}_{75}$ & $\mathrm{~A}_{60}$ \\
$\mathrm{H}_{4} \mathrm{y}$ & $\mathrm{G}_{30}$ & $\mathrm{C}_{60}$ & $\mathrm{~A}_{0}$ & $\mathrm{G}_{45}$ & $\mathrm{C}_{30}$ & $\mathrm{~A}_{15}$ & $\mathrm{~A}_{45}$ & $\mathrm{G}_{60}$ & $\mathrm{M}_{90}$ & $\mathrm{G}_{30}$ & $\mathrm{~A}_{45}$ & $\mathrm{~A}_{75}$ & $\mathrm{C}_{60}$ & $\mathrm{G}_{45}$ & $\mathrm{~A}_{0}$ & $\mathrm{C}_{30}$ & $\mathrm{G}_{60}$ \\
$\mathrm{H}_{5 y}$ & $\mathrm{C}_{0}$ & $\mathrm{C}_{30}$ & $\mathrm{C}_{45}$ & $\mathrm{~A}_{0}$ & $\mathrm{~A}_{60}$ & $\mathrm{~A}_{45}$ & $\mathrm{G}_{30}$ & $\mathrm{G}_{45}$ & $\mathrm{M}_{90}$ & $\mathrm{G}_{45}$ & $\mathrm{G}_{60}$ & $\mathrm{~A}_{45}$ & $\mathrm{~A}_{30}$ & $\mathrm{~A}_{0}$ & $\mathrm{C}_{45}$ & $\mathrm{C}_{60}$ & $\mathrm{C}_{0}$ \\
$\mathrm{H} 6 \mathrm{y}$ & $\mathrm{C}_{45}$ & $\mathrm{C}_{60}$ & $\mathrm{G}_{15}$ & $\mathrm{G}_{30}$ & $\mathrm{C}_{60}$ & $\mathrm{C}_{0}$ & $\mathrm{G}_{30}$ & $\mathrm{G}_{45}$ & $\mathrm{M}_{90}$ & $\mathrm{G}_{45}$ & $\mathrm{G}_{60}$ & $\mathrm{C}_{0}$ & $\mathrm{C}_{30}$ & $\mathrm{G}_{60}$ & $\mathrm{G}_{75}$ & $\mathrm{C}_{30}$ & $\mathrm{C}_{45}$ \\
$\mathrm{HE}$ & $\mathrm{M}_{90}$ & $\mathrm{M}_{90}$ & $\mathrm{M}_{90}$ & $\mathrm{M}_{90}$ & $\mathrm{M}_{90}$ & $\mathrm{M}_{90}$ & $\mathrm{M}_{90}$ & $\mathrm{M}_{90}$ & $\mathrm{M}_{90}$ & $\mathrm{M}_{90}$ & $\mathrm{M}_{90}$ & $\mathrm{M}_{90}$ & $\mathrm{M}_{90}$ & $\mathrm{M}_{90}$ & $\mathrm{M}_{90}$ & $\mathrm{M}_{90}$ & $\mathrm{M}_{90}$ \\
\hline
\end{tabular}

In order to enhance the adherence capacity of the fibers for the improvement of the properties and quality of fiber-matrix interface and to remove impurities, the plain fabrics were treated by uniform spaying with solutions made of detergent, sodium hydroxide and perchloric acid and then after each treatment were cleaned with water. The fiber stability during the cutting of the lamina and forming of the composites was provided by fabrics covering with a thin film made of mixed epoxy system with nitro diluent after their complete drying.

The difference between the materials of the classes Hx.1 and Hx.2 consists of epoxy matrix type. For the composites of class Hx.1 materials the epoxy resin was used as matrix while for the ones of class Hx.2 materials the epoxy resins was modified by dispersing various fillers. The stratified filled epoxy matrix was made of two types of fillers blend added into pre-polymer mixture intended for certain plies. The first filled epoxy matrix type, named here MF1, presents a mixture of potatoes starch, carbon black and aramid powder (each with 10\% wt.) used for plies 01 to 05 and 13 to17. The second filled epoxy matrix type, named here MF2, is a mixture of potatoes starch, carbon black and barium ferrite (each with $10 \%$ wt.) used for the plies 06 to 12 .

All epoxy composite materials reinforced with fabrics for this investigation were formed by wet layup technique and after complete polymerization they were thermally cured.

\subsection{Details of thermal measurements}

The measurements of specific heat and thermal expansion coefficient were performed by using the instruments Mettler Toledo and data acquisition and evaluation software STARe. So, the thermomechanical analyzer TMA SDTA 840 instrument was used for investigation of thermal linear expansion coefficient with $20^{\circ} \mathrm{C} / \mathrm{min}$ heating ratio in the temperature domain of $30-200^{\circ} \mathrm{C}$. The shape of used specimens was rectangular with $10 \times 5 \mathrm{~mm}$ dimensions of the surface. The measurements of thermal linear expansion coefficient were performed on the plane of the reinforcement. The typical thickness vs. temperature curve of thermomechanical measurements of a hybrid epoxy composite is plotted in Figure 1.

Differential Scanning Calorimeter (DSC 1) instrument was used to analyze the specific heat of the hybrid epoxy laminates with $20^{\circ} \mathrm{C} / \mathrm{min}$ heating/cooling ratios on the temperature domain of $30-330^{\circ} \mathrm{C}$. 
The shape of used specimens for specific heat measurements was cylindrical with $3 \mathrm{~mm}$ surface diameter. In Figure 2 are plotted the typical heat flow and specific heat vs temperature of DSC measurements.



Figure 1. Typical thickness vs. temperature curve of thermomechanical measurements

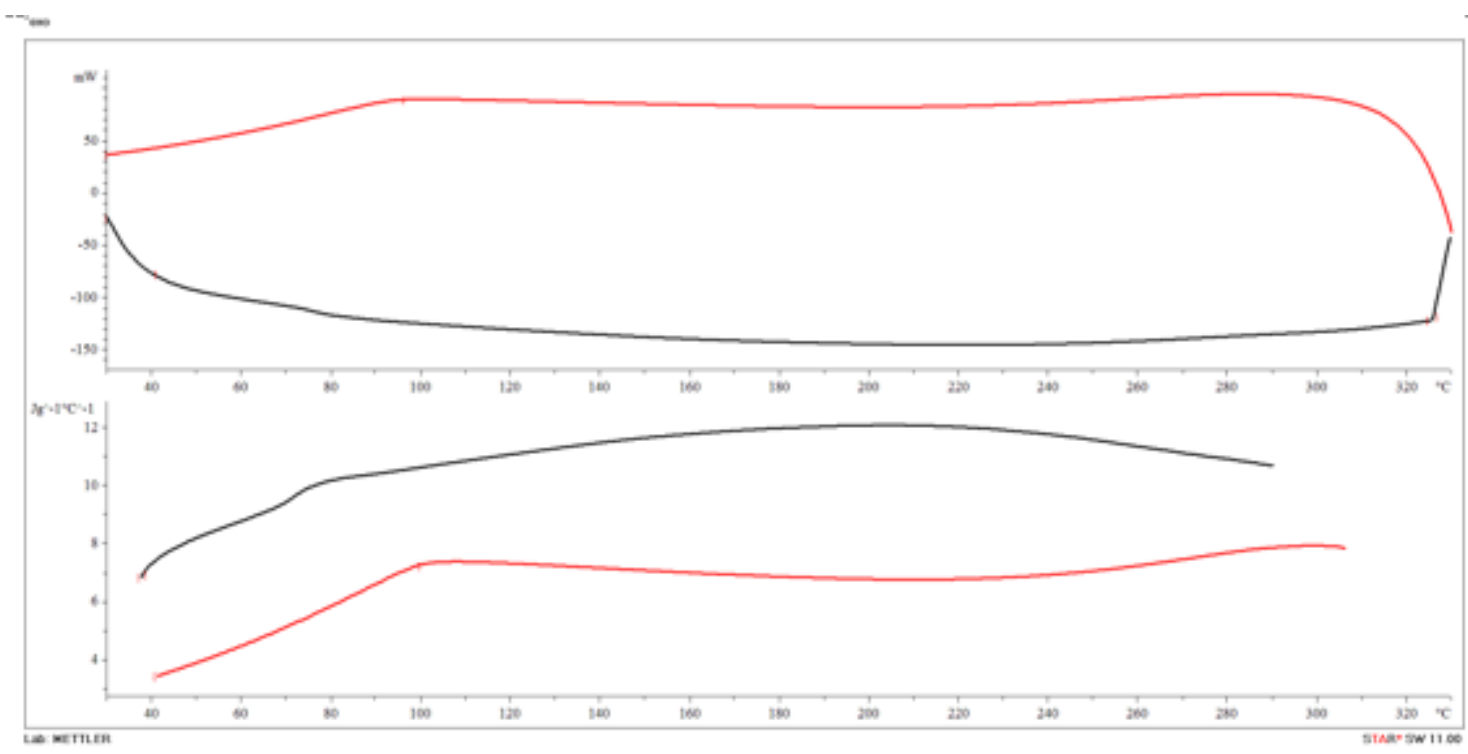

Figure 2. Typical heat flow vs. temperature (above) and specific heat vs. temperature (below) of DSC measurements

\section{Results and discussions}

The investigation of thermal properties of the hybrid epoxy composites reinforced with fabrics was performed on the linear limits of measurement curve part. So, the values of thermal coefficient of linear expansion were recorded on the linear segment of the thickness vs. temperature curves and those of specific heat were determined on the linear segments of specific heat vs. temperature curves on cooling, which are presented in Figures 1 and 2. Based on the curves obtained after the performed thermal measurements, the values of linear expansion coefficient and specific heat of hybrid epoxy composites were calculated in the temperature ranges of $40-60^{\circ} \mathrm{C}$ and $110-170^{\circ} \mathrm{C}$.

In Figures 3 and 4 are plotted the averaged values of thermal expansion coefficient of the hybrid epoxy composites with unfilled matrix (Figure 3) and stratified filled matrix (Figure 4) evaluated on the temperature domains of $40-60^{\circ} \mathrm{C}$ and $110-170^{\circ} \mathrm{C}$. If we compare the hybrid composites with unfilled matrix and outer layers made of aramid fabric (Figure 3), in case of composite materials H11 and H21, 
the values of thermal expansion coefficient decreased by replacement of carbon plies 5 and 13 of the hybrid composite H11 with glass lamina with the same fiber orientation and by modifying of its fiber orientation of the other plies.

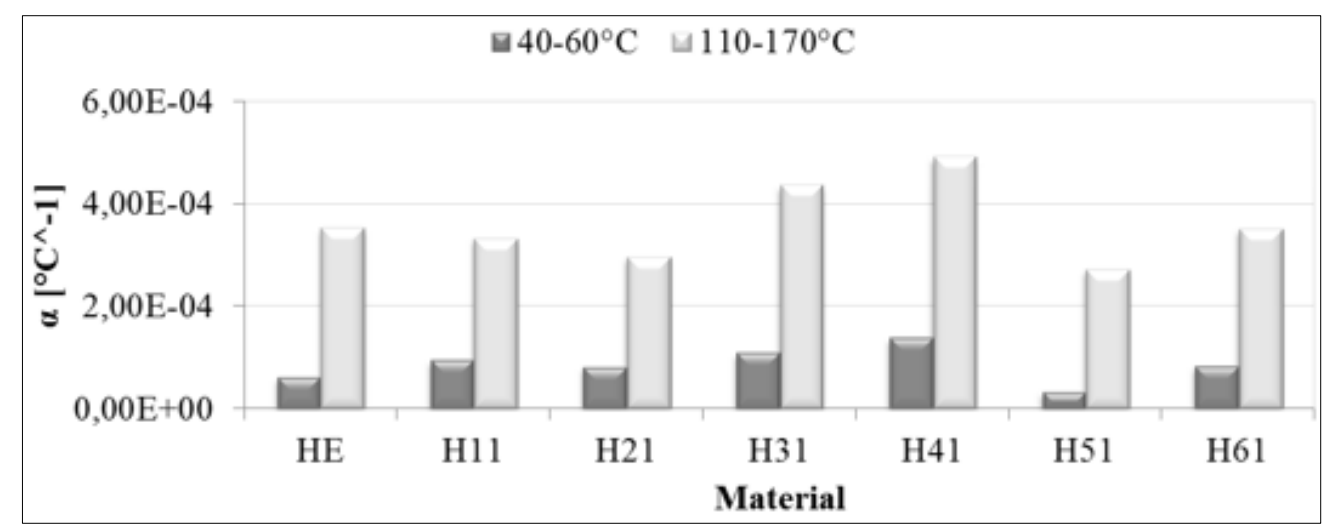

Figure 3. Thermal coefficient of linear expansion of hybrid epoxy composites with unfilled matrix

In case of composite materials $\mathrm{H} 21$ and $\mathrm{H} 31$, it was observed that the replacement of carbon plies 4 and 14 of the hybrid composite $\mathrm{H} 21$ with glass lamina with fiber orientation at $45^{\circ}$ and change of its fiber orientation of the other plies led to an increasing in coefficient values higher than those exhibited by composite material H11. The highest value of thermal expansion coefficient was recorded in case of composite material with outer plies made of glass fabric. Regarding the thermomechanical behavior of composites with carbon outer layers (H51 and H61) depending on the number of glass layers, it was obtained that the one with less glass layers (H51) showed the lowest value of thermal coefficient. Generally, the lowest thermal coefficient was presented by composite H51, relative to which the composite reinforced with only hybrid fabric $\mathrm{HE}$ exhibited values of thermal coefficient higher by almost 45 and $23 \%$ in the temperature ranges $40-60^{\circ} \mathrm{C}$ and $110-170^{\circ} \mathrm{C}$ respectively.

In Figure 4 it can be seen the influence of the fillers on the thermomechanical behavior of the hybrid epoxy composites reinforced with fabrics. It can be observed that addition of the fillers into epoxy matrix led to a volume change by contraction of the composite materials with carbon outer plies, whose thermal coefficient showed negative values in the temperature range of $40-60^{\circ} \mathrm{C}$.

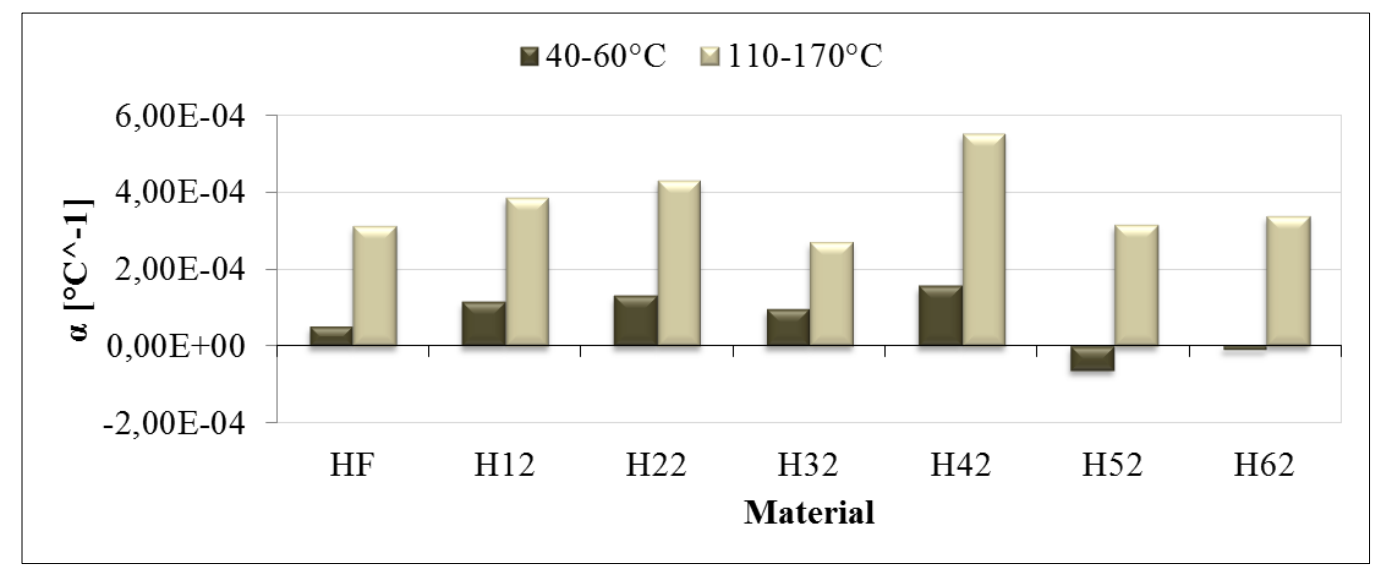

Figure 4. Thermal coefficient of linear expansion of hybrid epoxy composites with filled matrix

The highest negative value was obtained in case of the composite with less glass layers H52, but a good structural stability in the temperature range of $40-60^{\circ} \mathrm{C}$ was showed by the composite with carbon outer plies and more inner glass plies H62. Regarding the thermal coefficient measured in the 
temperature range of $110-170^{\circ} \mathrm{C}$ of these materials, it was recorded that the values of this coefficient increased by almost $15 \%$ in case of composite $\mathrm{H} 52$ and decreased by almost $3 \%$ in case of composite H62. Also, the filler addition into epoxy matrix led to a decreasing of the thermal expansion coefficient on both temperature ranges for composites reinforced with hybrid fabric (HF) by almost $17 \%$ and $12 \%$ respectively and for composite material with aramid outer plies and only glass plies 5 and 13 (H32) by almost 12 and 38\% respectively. Generally, the epoxy composites reinforced with hybrid fabric HE and HF showed medial values of thermal expansion coefficient between minimum and maximum values of hybrid composites.

The averaged values of specific heat in cooling temperature ranges presented by hybrid composites with unfilled epoxy matrix are plotted in Figure 5. The composite reinforced with hybrid fabric showed approximately the same values between minimum and maximum values of hybrid composites on both cooling temperature ranges. The specific heat of hybrid composites with aramid outer plies without inner glass plies exhibited higher values than those of composite reinforced with hybrid fabric. It can be observed that the values of this composite are higher in the temperature range of $40-60^{\circ} \mathrm{C}$ as compared to those measured in the temperature range of $110-170^{\circ} \mathrm{C}$. It can be seen that the replacement of certain inner carbon plies with glass layers and the modification of fiber orientation, in case of hybrid composites with aramid outer plies influences insignificantly the specific heat in the temperature range of $40-60^{\circ} \mathrm{C}$ and leads to an increase of this thermal parameter in the temperature range of $110-170^{\circ} \mathrm{C}$. During cooling on the specified temperatures ranges the lowest specific heat was recorded for hybrid epoxy composite with glass outer plies. The hybrid composites with outer carbon layers exhibited approximately the same values of specific heat on both temperature ranges.

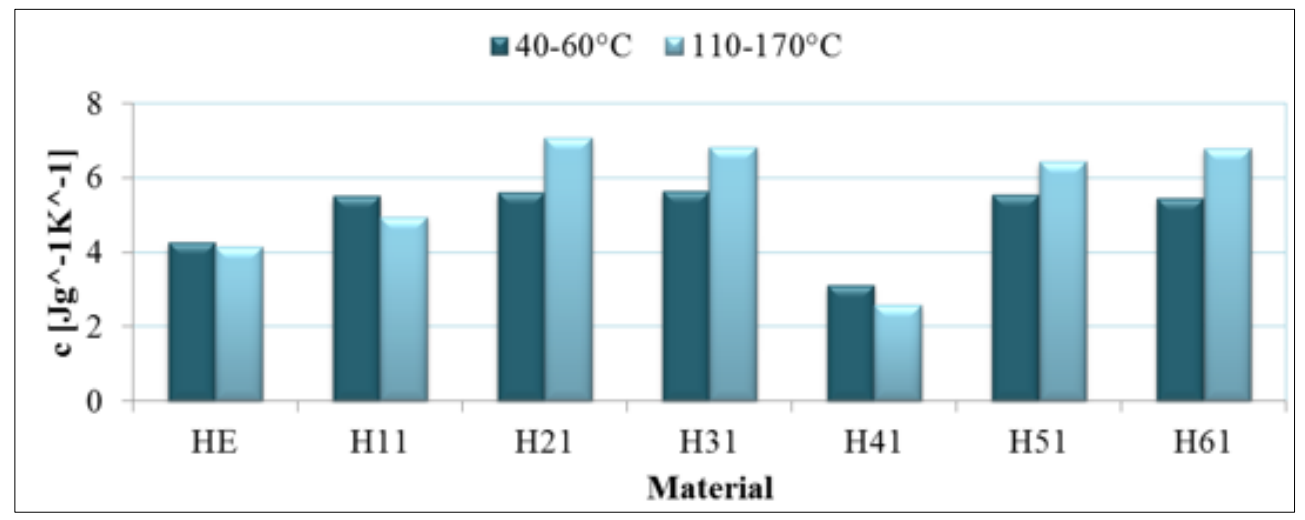

Figure 5. Specific heat of hybrid epoxy composites with unfilled matrix measured on the targeted temperature domains

The influence of fillers on specific heat of the hybrid composites on cooling segments of analysis on the selected temperatures domains can be investigated in Figure 6. The addition of fillers into epoxy matrix led to a decreasing of specific heat for the composite reinforced with hybrid fabric in the cooling temperature ranges by almost 23 and $4 \%$ respectively. In the case of hybrid composites with aramid outer plies without inner glass plies, it was recorded an insignificant increasing of specific heat on both cooling temperature ranges.

The fillers addition into epoxy matrix of the composites with outer aramid and inner glass plies influenced insignificantly their specific heat on both temperature ranges. In the case of hybrid epoxy composite with glass outer plies, the specific heat on cooling in the temperature ranges increased by 45 and $67 \%$ respectively due to filler mixtures. The hybrid composites with outer carbon and inner aramid plies exhibited an insignificant increasing of specific heat for both temperatures ranges. The addition of filler mixtures into epoxy matrix of the hybrid epoxy composite with outer carbon plies and without inner aramid plies led to a significant decrease of the specific heat by almost $68 \%$ on both temperature ranges during cooling. 


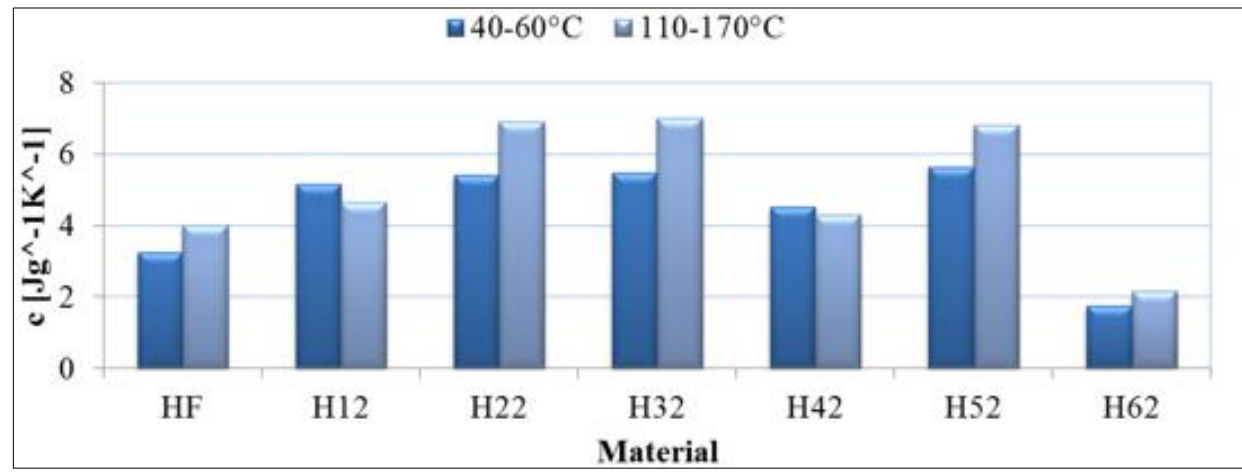

Figure 6. Specific heat of hybrid epoxy composites with filled matrix measured on the targeted temperature domains

\section{Conclusions}

The thermal parameters, as thermal linear expansion coefficient and specific heat of fabric reinforced hybrid epoxy composites with ply orientation at various angles measured by Thermomechanical Analysis (TMA) and Differential Scanning Calorimeter (DSC), respectively, were studied. It was, also, analyzed the influence of the carbon black - aramid powder and carbon black - barium ferrite mixtures added into epoxy matrix between certain layers of the hybrid composites. Based on the obtained experimental data investigated in the temperature ranges of $40-60^{\circ} \mathrm{C}$ and $110-170^{\circ} \mathrm{C}$, the following conclusions can be drawn:

- The hybrid composite material with glass outer plies showed the highest thermal linear expansion coefficient, so as the replacement of certain carbon inner plies of hybrid composite with unfilled matrix and aramid outer layers with glass lamina and the modification of its other plies orientation led to a variation of the thermal expansion coefficient values. The lowest value of thermal coefficient was recorded in case of the composite with carbon outer layers H51. The epoxy composite reinforced with hybrid fabric presented higher values of thermal expansion coefficient on both temperature ranges by almost 45 and $23 \%$ respectively as compared to hybrid composite H51.

- The addition of the carbon black - aramid powder and carbon black - barium ferrite mixtures into epoxy matrix led to the decreasing of thermal expansion coefficient to negative values in the temperature range of $40-60^{\circ} \mathrm{C}$ in case of the composite materials with carbon outer plies. The hybrid composite H52 presented the highest negative value of this parameter and the hybrid composite H62 showed a good structural stability in this temperature range. The specific heat of the hybrid epoxy composite with outer carbon plies and without inner aramid plies H62 decreased by almost $68 \%$ on both temperature ranges.

- The thermal expansion coefficient of the composite reinforced with hybrid fabric (HF) was reduced on both temperature ranges for by almost 17 and $12 \%$ respectively and its specific heat decreased in the cooling segment in the targeted temperature ranges by almost $23 \%$ and $4 \%$ respectively.

Acknowledgments: This work is supported by the project ANTREPRENORDOC, in the framework of Human Resources Development Operational Programme 2014-2020, financed from the European Social Fund under the contract number 36355/23.05.2019 HRD OP /380/6/13 - SMIS Code: 123847.

\section{References}

1.NAZARENKO, O.B., MELNIKOVA, T.V., VISAKH, P.M., Thermal and Mechanical Characteristics of Polymer Composites Based on Epoxy Resin, Aluminium Nanopowders and Boric Acid, Journal of Physics: Conference Series, 671, 2016, 012040. https://doi.org/10.1088/1742-6596/671/1/012040

2.JAMALUDIN, N., ANITHAMBIGAI, P., SHANMUGAN, S., MUTHARASU, D., Performance and Thermal Analysis of Aluminium Oxide Filled Epoxy Composite as TIM for LEDs, Material Science Research India, 11, 2014, 35-41. https://doi.org/10.13005/msri/110105 
3.YUSOFF, P.M., AHMAD, F., AMIR, N., LEONG, S.F., RUSOP, M., SUBBAN, R.Y., KAMARULZAMAN, N., WUI, W.T., Effect Of Particle Dispersion On Thermal Conductivity Of Copper Powder Filled Epoxy Composites, International conference on advancement of materials and nanotechnology (ICAMN-2007), Langkawi, Kedah (Malaysia), 2010.

4.MOHD HIRMIZI, N.H., ABU BAKAR, M., TAN, W.L., ABU BAKAR, N.H.H., ISMAIL, J., SEE, C.H., Electrical and Thermal Behavior of Copper-Epoxy Nanocomposites Prepared via Aqueous to Organic Phase Transfer Technique, Journal of Nanomaterials, 2012, 2012, 1-11.

https://doi.org/10.1155/2012/219073

5.NIKKESHI, S., KUDO, M., MASUKO, T., Dynamic viscoelastic properties and thermal properties of Ni powder-epoxy resin composites, Journal of Applied Polymer Science, 69, 1998, 2593-2598. https://doi.org/10.1002/(SICI)1097-4628(19980926)69:13<2593::AID-APP9>3.0.CO;2-5

6.CHEN, L., ZHAO, P., XIE, H., YU, W., Thermal properties of epoxy resin based thermal interfacial materials by filling Ag nanoparticle-decorated graphene nanosheets, Composites Science and Technology, 125, 2016, 17-21. https://doi.org/10.1016/j.compscitech.2016.01.011

7.RIVIÈRE, L., CAUSSÉ, N., LONJON, A., DANTRAS, É., LACABANNE, C., Specific heat capacity and thermal conductivity of PEEK/Ag nanoparticles composites determined by Modulated-Temperature Differential Scanning Calorimetry, Polymer Degradation and Stability, 127, 2016, 98-104. https://doi.org/10.1016/j.polymdegradstab.2015.11.015

8.HU, Y., DU, G., CHEN, N., A novel approach for Al $2 \mathrm{O} 3$ /epoxy composites with high strength and thermal conductivity, Composites Science and Technology, 124, 2016, 36-43.

https://doi.org/10.1016/j.compscitech.2016.01.010

9.PERMAL, A., DEVARAJAN, M., HUNG, H.L., ZAHNER, T., LACEY, D., IBRAHIM, K., Thermal and mechanical properties of epoxy composite filled with binary particle system of polygonal aluminum oxide and boron nitride platelets, Journal of Materials Science, 51, 2016, 7415-7426.

https://doi.org/10.1007/s10853-016-0016-3

10.TEJA, M.S., RAMANA, M.V., SRIRAMULU, D., RAO, C.J., Experimental investigation of mechanical and thermal properties of sisal fibre reinforced composite and effect of SiC filler material, IOP Conference Series: Materials Science and Engineering, 149, 2016, 012095.

https://doi.org/10.1088/1757-899X/149/1/012095

11.ZHOU, T., WANG, X., CHENG, P., WANG, T., XIONG, D., WANG, X., Improving the thermal conductivity of epoxy resin by the addition of a mixture of graphite nanoplatelets and silicon carbide microparticles, Express Polymer Letters, 7, 2013, 585-594.

https://doi.org/10.3144/expresspolymlett.2013.56

12.ZHENG, X., KIM, S., PARK, C.W., Enhancement of thermal conductivity of carbon fiber-reinforced polymer composite with copper and boron nitride particles, Composites Part A: Applied Science and Manufacturing, 121, 2019, 449-456. https://doi.org/10.1016/j.compositesa.2019.03.030

13.MI X, ZHONG L, WEI F, ZENG L, ZHANG J, ZHANG D, XU T, Fabrication of halloysite nanotubes/reduced graphene oxide hybrids for epoxy composites with improved thermal and mechanical properties, Polymer Testing, 76, 2019, 473-80. https://doi.org/10.1016/j.polymertesting.2019.04.007

14.DU, F., GUTHY, C., KASHIWAGI, T., FISCHER, J.E., WINEY, K.I., An infiltration method for preparing single-wall nanotube/epoxy composites with improved thermal conductivity, Journal of Polymer Science Part B: Polymer Physics, 44, 2006, 1513-1519. https://doi.org/10.1002/polb.20801

15.CARADONNA, A., BADINI, C., PADOVANO, E., PIETROLUONGO, M., Electrical and Thermal Conductivity of Epoxy-Carbon Filler Composites Processed by Calendaring, Materials, 12, 2019, 1522. https://doi.org/10.3390/ma12091522

16.KOSTAGIANNAKOPOULOU, C., FIAMEGKOU, E., SOTIRIADIS, G., KOSTOPOULOS, V., Thermal Conductivity of Carbon Nanoreinforced Epoxy Composites, Journal of Nanomaterials, 2016, 2016, 1-12. https://doi.org/10.1155/2016/1847325 
17.ASHRAFI M, GHASEMI AR, HAMADANIAN M, Optimization of thermo-mechanical and antibacterial properties of epoxy/polyethylene glycol/MWCNTs nano-composites using response surface methodology and investigation thermal cycling fatigue, Polymer Testing, 78, 2019, 105946. https://doi.org/10.1016/j.polymertesting.2019.105946

18.DATSYUK V, TROTSENKO S, TRAKAKIS G, BODEN A, VYZAS-ASIMAKOPOULOS K, PARTHENIOS J, GALIOTIS C, REICH S, PAPAGELIS K, Thermal properties enhancement of epoxy resins by incorporating polybenzimidazole nanofibers filled with graphene and carbon nanotubes as reinforcing material, Polymer Testing, 82, 2020, 106317.

https://doi.org/10.1016/j.polymertesting.2019.106317

19.SHI, Z., LI, X.-F., BAI, H., XU, W.-W., YANG, S.-Y., LU, Y., HAN, J.-J., WANG, C.-P., LIU, X.J., LI, W.-B., Influence of microstructural features on thermal expansion coefficient in graphene/epoxy composites, Heliyon, 2, 2016, e00094. https://doi.org/10.1016/j.heliyon.2016.e00094

20.SHEN, X., WANG, Z., WU, Y., LIU, X., KIM, J.-K., Effect of functionalization on thermal conductivities of graphene/epoxy composites, Carbon, 108, 2016, 412-422.

https://doi.org/10.1016/j.carbon.2016.07.042

21.BERA, T., ACHARYA, S.K., MISHRA, P., Synthesis, mechanical and thermal properties of carbon black/epoxy composites, International Journal of Engineering, Science and Technology, 10, 2018, 1220. https://doi.org/10.4314/ijest.v10i4.2

22.MA, A.-J., CHEN, W., HOU, Y., ZHANG, G., Dispersion, Mechanical and Thermal Properties of Epoxy Resin Composites Filled with the Nanometer Carbon Black, Polymer-Plastics Technology and Engineering, 49, 2010, 916-920. https://doi.org/10.1080/03602551003773122

23.AHMED, A., TAVAKOL, B., DAS, R., JOVEN, R., ROOZBEHJAVAN, P., MINAIE, B., Study of thermal expansion in carbon fiberreinforced polymer composites, International SAMPE Technical Conference, 2012.

24.PRAVEEN, R.S., JACOB, S., MURTHY, C.R.L., BALACHANDRAN, P., RAO, Y.V.K.S., Hybridization of carbon-glass epoxy composites: An approach to achieve low coefficient of thermal expansion at cryogenic temperatures, Cryogenics, 51, 2011, 95-104.

https://doi.org/10.1016/j.cryogenics.2010.12.003

25.CAPATINA, A., BRIA, V., BUNEA, M., BIRSAN, I.-G., Tensile Behaviour of Fabric Reinforced Laminates and Plies, Mater. Plast., 56(2), 2019, 370-377. https://doi.org/10.37358/MP.19.2.5188

26.BRIA, V., CÎRCIUMARU, A., BÎRSAN, I.G., Some Properties of Starch/Epoxy Composites, Mater. Plast., 48(2), 2011, 189-194.

27.BUNEA, M., BOSOANCA, R., COJAN, A., BIRSAN, I.G., Thermomechanical and Electrical Properties of Fabric Reinforced Laminates with Filled Stratified Epoxy Matrix, Mater. Plast., 55(3), 2018, 269-273. https://doi.org/10.37358/MP.18.3.5011

28.STEFANESCU, V., BOBOC, A., COJAN, A., BOSOANCA, R., MUNTENITA, C., BUNEA, M., The Thermal Behavior of Hybrid Fabric Reinforced Composites with Stratified Filled Epoxy Matrix, Mater. Plast., 55 (2), 2018, 161-166. https://doi.org/10.37358/MP.18.2.4986

Manuscript received: 12.05 .2020 